\title{
Структура цементного камня, модифицированного нанодисперсной титаносодержащей добавкой
}

\author{
Тюкавкина В.В., Цырятьева А.В.
}

Институт химии и технологии редких элементов и минерального сырья им. И.В. Тананаева ФИЦ КНЦРАH, tukav_vv@chemy.kolasc.net.ru

Аннотация. Изучено влияние диоксида титана, полученного из отработанного при очистке стоков с цветными тяжелыми металлами сорбента, на процессы структурообразования портландцементного камня. При помощи РФА и ДТА выявлено, что введение в состав цементной композиции нано-ТіО2 оказывает ускоряющее действие на гидратацию силикатов кальция, образование гидросиликатов кальция и способствует уменьшению содержания портландита. Структура цементного камня, модифицированного нанодисперсным диоксидом титана, характеризуется присутствием на его поверхности пластинок титаната кальция, а также наличием в микропорах более развитых игольчатых кристаллов гидросиликатов кальция и волокон тоберморитового геля, которые способствуют снижению дефектности структуры, повышению плотности и прочности цементного камня.

Ключевые слова: диоксид титана, структурообразование, гидратация, цементный камень, прочность, плотность.

\section{The structure of the cement stone modified by nanodispersed titanium-bearing additive}

Tyukavkina V.V., Tsyryatyeva A.V.

Tananaev Institute of Chemistry - Subdivision of the Federal Research Centre Kola Science Centre of the Russian Academy of Sciences, Science Centre of Russian Academy of Sciences (FRC KSC RAS), tukav_vv@chemy.kolasc.net.ru

\begin{abstract}
The effect of titanium dioxide, obtained from the sorbent used to treat wastes with non-ferrous heavy metals on the structure formation of a Portland cement stone was studied. With the help of X-ray diffraction analysis and DTA, it is revealed that the introduction of nano- $\mathrm{TiO}_{2}$ into the cement composition has an accelerating effect on the hydration of calcium silicates, the formation of calcium hydrosilicates and contributes to a decrease in the content of portlandite. The structure of the cement stone modified with nanodispersed titanium dioxide is characterized by the presence of calcium titanate plates on its surface, as well as by the presence of more developed needles of calcium hydrosilicates and tobermorite gel in micropores that reduce the structure's defectiveness, increase the density and strength of the cement stone.
\end{abstract}

Key words: titanium dioxide, structure formation, hydration, cement stone, durability, density.

Одним из эффективных способов получения строительных конгломератов с уникальными физико-химическими свойствами является модификация структуры путем введения нанодисперсных добавок. Лучшее понимание структуры цементного камня помогает влиять на характеристики и процессы, связанные с производством и использованием строительных материалов, и является важным инструментом в создании строительных материалов с заданными специальными свойствами. Большинство работ в области применения наночастиц для направленного улучшения характеристик бетона связано с применением нано- $\mathrm{SiO}_{2}$, проведена большая работа по использованию нано- $\mathrm{TiO}_{2}$ (Копаница и др., 2016; Li et al., 2016).

$\mathrm{B}$ качестве добавки нано- $\mathrm{TiO}_{2}$ применяется для самоочищающегося бетона, способного обеспечивать чистоту воздушного бассейна мегаполисов. Результаты лабораторных исследований свидетельствуют о высокой эффективности данных материалов при нейтрализации различных газообразных выбросов, загрязняющих воздух, таких как $\mathrm{NO}_{\text {x }}$ CO и др. (Macphee et al., 2016; Ляпидевская и др., 2014). Фотокаталитические бетоны уже применяются в Европе, Японии, США. Кроме того нано- $\mathrm{TiO}_{2}$ может ускорить гидратацию портландцемента, улучшить прочностные характеристики, повысить износостойкость бетона (Вила Гомез, 2013). Проведенными ранее исследованиями 
установлено, что порошок нанодисперсного диоксида титана, полученный из отработанного сорбента, упрочняет цементный камень и придает ему способность к самоочищению за счет фотохимической активности введенной добавки (Тюкавкина и др., 2016). Однако, для эффективного, целенаправленного управления процессом структурообразования необходимо изучить процессы, происходящие при твердении цементного камня, модифицированного нано- $\mathrm{TiO}_{2}$, и установить роль добавки в формировании структуры бетона.

В задачу данного исследования входило изучение влияния добавки диоксида титана, полученного из отработанного при очистке стоков с цветными тяжелыми металлами сорбента на процессы твердения и фазовый состав продуктов гидратации портландцементного камня.

Порошок диоксида титана, используемый для исследований в качестве добавки в цемент был получен из отработанного гранулированного сорбента, который использовался при очистке жидких стоков от катионов $\mathrm{Co}^{2+}$ (Gerasimova et al., 2013; Герасимова и др., 2015). Разрушенные в процессе эксплуатации гранулы подвергали термообработке при $75^{\circ} \mathrm{C}$. Порошок диоксида титана содержал 70.3 мас. \% $\mathrm{TiO}_{2}$ в виде анатаза, 4.7 мас. \% $\mathrm{CoO}$, остальное вода. Удельная поверхность $\left(\mathrm{S}_{\text {уд. }}\right)$ диоксида титана составляла $248 \mathrm{~m}^{2} / \Gamma$, объем пор - 0,167 см $3 /$, размер частиц (расчетный по $\mathrm{S}_{\text {уд. }}$ ) 6.2 нм. В качестве вяжущего использовали цемент CEM II/A-V 42.5R (Норвегия).

Для изучения процессов происходящих при твердении цементного камня, модифицированного добавкой нанодисперсного диоксида титана из цементного теста нормальной густоты готовили образцы размерами $2 \times 2 \times 2 \mathrm{~cm}$, которые твердели при температуре $20 \pm 2{ }^{\circ} \mathrm{C}$ и относительной влажности воздуха 90-95 \%. Для предотвращения агломерации и максимального разделения частиц $\mathrm{TiO}_{2}$ в объеме цементной матрицы порошки предварительно подвергали ультразвуковому диспергированию в водной среде в течение 10 минут при помощи ультразвукового диспергатора УЗД 2-0,1/22, генерирующего ультразвуковое поле с частотой 22 кГц и мощностью 0.2 Квт. При приготовлении образцов полученную при диспергировании суспензию смешивали с цементом в лабораторном автоматическом смесителе. Через определенные промежутки времени образцы испытывали на прочность при сжатии, затем из центра образца отбирали часть материала для дальнейших исследований.

Фазовый состав гидратированных материалов определяли с помощью рентгенофазового и дифференциально-термического методов анализа. Рентгенограммы снимали на приборе ДРОН-2 со скоростью 2 град/мин в диапазоне $2 \Theta=6-180^{\circ}$. Дифференциально-термический анализ проводили на приборе системы Ф. Паулик, И. Паулик, Л. Эрдеи (ОД 102-568/c). Структуру затвердевшего материала и состав фаз изучали при помощи сканирующего электронного микроскопа LEO 420 фирмы «ZEISS» (Германия) оснащённом энергодисперсионным спектрометром INCA Energy 400 фирмы «OXFORD Instrument» (Великобритания).

Изучение физико-химических процессов гидратации и продуктов твердения цементного камня модифицированного добавкой диоксида титана при помощи рентгенофазового, термографического (ДТА) анализов показали, что нанодисперсные частицы $\mathrm{TiO}_{2}$ оказывают ускоряющее действие на гидратацию силикатов кальция с образованием гидросиликатов кальция. По данным рентгенофазового анализа при введении нанодисперсной добавки $\mathrm{TiO}_{2}$ на дифрактограмме наблюдается уменьшение рефлексов клинкерных минералов и увеличение рефлексов, принадлежащих гидросиликатам кальция (CSH), а также уменьшение интенсивности пика портландита $\left(\mathrm{Ca}(\mathrm{OH})_{2}\right)$ (рис. 1).

Выполненный дифференциально-термический анализ согласуется с результатами РФА. Потери массы цементного камня, связанные с дегидратацией портландита, гидросиликатов кальция и эттрингита, определенные по кривым ТГ ДТА приведены в таблице 1. На всех дифференциальнотермических кривых в интервале $120-140^{\circ} \mathrm{C}$ присутствует ярко выраженный эндотермический эффект, свидетельствующий о частичной дегидратации фазы CSH, эттрингита и в области температур 490-500 ${ }^{\circ} \mathrm{C}$ эндоэффект, соответствующий разложению портландита. Как видно из приведенных в таблице данных, в образцах, содержащих $\mathrm{TiO}_{2}$, наблюдается увеличение потери массы гигроскопичной воды, что указывает на повышенное содержание гидросиликатов кальция и эттрингитта, а также уменьшение потери массы при температуре $490^{\circ} \mathrm{C}$, соответствующей разложению портландита, все это способствует повышению прочности и плотности цементного камня (табл. 1). 


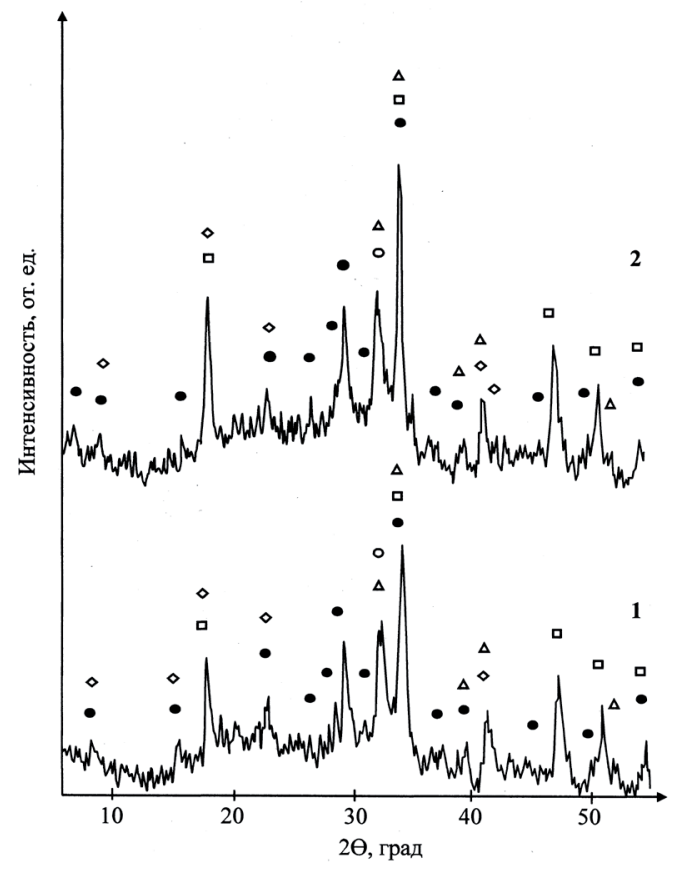

Рис. 1. Рентгенограммы образцов цементного камня после 28 сут. твердения, содержащего 2 мас. \% $\mathrm{TiO}_{2}$ (кривая 1) и контрольного состава (кривая 2); • - гидросиликаты, $\Delta-$ белит, $\square-$ портландит, $\diamond-$ эттрингит, о - алит.

Fig. 1. XRD-patterns of cement stone samples after 28 days of hardening, using 2 wt. $\% \mathrm{TiO}_{2}$ (curve 1) and control composition (curve 2); - - hydrosilicates, $\Delta$ - belite, $\square-$ portlandite, $\diamond$ - ettringite, $\circ-$ alite. на, характеризуется присутствием на его поверхности пластинок титаната кальция, а также наличием в микропорах более развитых игольчатых кристаллов гидросиликатов кальция и волокон тоберморитового геля, которые способствуют повышению плотности цементного камня и снижению дефектности структуры.

Таблица 1. Термографические исследования цементного камня, модифицированного добавкой

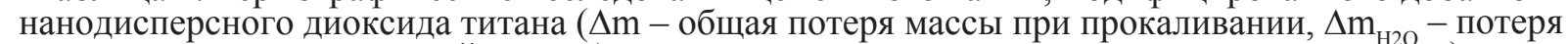
массы гигроскопичной воды, $\Delta \mathrm{m}_{\mathrm{Ca}(\mathrm{OH}) 2}$ - потеря массы при разложении портландита).

Table 1. Thermographic studies of the cement stone modified with addition of nanosized titanium dioxide ( $\Delta \mathrm{m}$ - total mass loss on ignition, $\Delta \mathrm{m}_{\mathrm{H} 2 \mathrm{O}}$ - mass loss of hygroscopic water, $\Delta \mathrm{m}_{\mathrm{Ca}(\mathrm{OH}) 2}-$ mass loss during the decomposition of portlandite).

\begin{tabular}{|c|c|c|c|c|c|c|c|}
\hline $\begin{array}{c}\text { Кол-во } \\
\text { добавки, } \\
\text { мас. \% }\end{array}$ & $\begin{array}{c}\text { Время } \\
\text { твердения, } \\
\text { сут. }\end{array}$ & $\Delta \mathrm{m}, \%$ & $\begin{array}{l}\Delta \mathrm{m}_{\mathrm{H} 2 \mathrm{O}} \\
\text { мac. } \%\end{array}$ & $\begin{array}{l}\Delta \mathrm{m}_{\mathrm{Ca}(\mathrm{OH}) 2} \\
\text { мac. } \%\end{array}$ & $\begin{array}{c}\text { Эндоэффекты } \\
\text { при температуре, } \\
{ }^{\circ} \mathrm{C}\end{array}$ & $\begin{array}{c}\text { Прочность } \\
\text { при сжатии, } \\
\text { МПа }\end{array}$ & 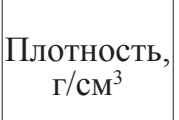 \\
\hline \multirow{3}{*}{0} & 3 & 23.62 & 6.90 & 2.70 & 120.500 & 65.7 & 2.11 \\
\hline & 7 & 24.14 & 8.36 & 2.01 & 125.490 & 77.8 & 2.12 \\
\hline & 28 & 25.7 & 9.46 & 2.03 & 125.490 & 81.9 & 2.13 \\
\hline \multirow{3}{*}{2} & 3 & 22.05 & 8.28 & 1.34 & 130.490 & 89.9 & 2.14 \\
\hline & 7 & 22.42 & 8.97 & 1.38 & 130.490 & 93.6 & 2.17 \\
\hline & 28 & 22.51 & 10.07 & 1.32 & 140.495 & 97.6 & 2.18 \\
\hline
\end{tabular}



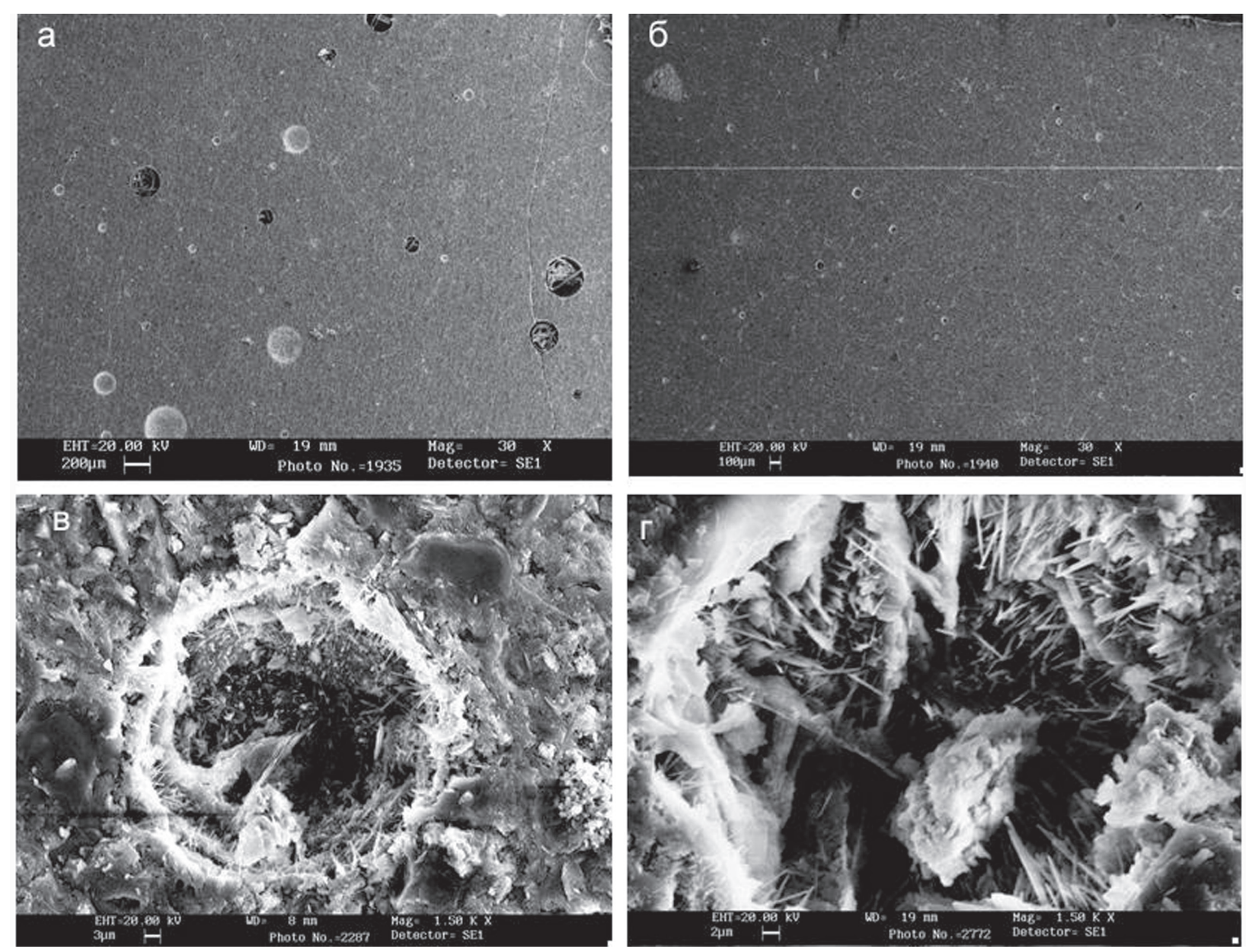

Рис. 2. Структура цементного камня в возрасте 28 сут без $\mathrm{TiO}_{2}$ (а, в) и с 2 мас. $\% \mathrm{TiO}_{2}(б$, г)

Fig. 2. The structure of cement stone at the age of 28 days without $\mathrm{TiO}_{2}\left(\right.$ (а, в) and $2 \mathrm{wt}$. $\% \mathrm{TiO}_{2}(б$, г)

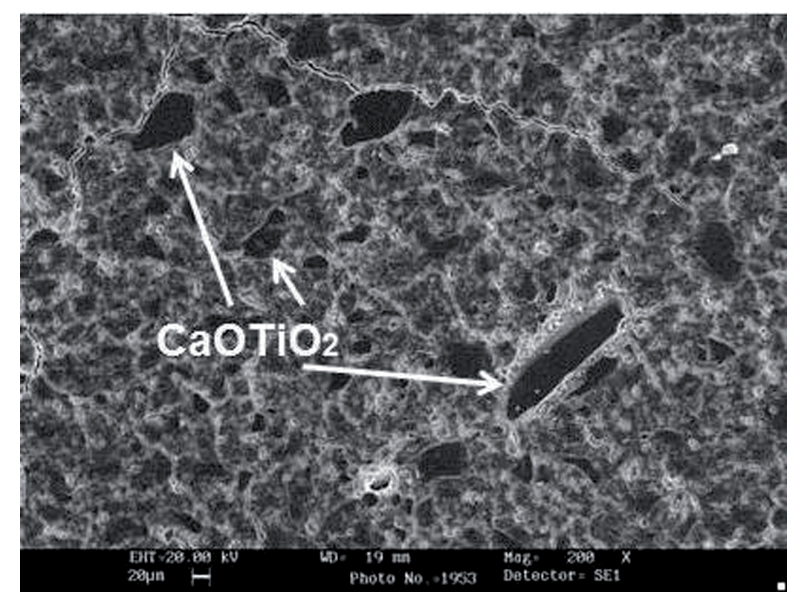

Рис. 3. Микрофотография поверхности цементного камня, модифицированного диоксидом титана.

Fig. 3. Micrograph of the surface of cement stone modified by titanium dioxide.

\section{Литература}

1. Богач М., Станек Т., Вшианский Д. Свойства композиций на основе цемента с добавками наночастиц диоксида титана // Цемент и его применение. 2011. № 5. С. 162-166.

2. Вила Гомез Х. Обзор по $\mathrm{TiO}_{2}$ - фотокатализ и некоторые виды его применения в строительной промышленности. «ALITinform» Международное аналитическое обозрение. 2013. № 4-5(31). С. 72-87.

3. Копаница Н.О., Саркисов Ю.С., Демьяненко О.В. Применение нанодисперсного кремнезема в производстве строительных смесей // Вестник ТГАСУ. 2016. № 5. С. 140-150. 
4. Ляпидевская О.Б., Фрайнт М.А. Фотокаталитический бетон для дорожного строительства. Вестник МГСУ. 2014. № 2. С. 125-130.

5. Пат. 2568699 РФ, МПК В01J 20/02, С01В 33/20 (2006.01). Способ получения натрийсодержащего титаносиликата / Герасимова Л.Г., Николаев А.И., Щукина Е.С. и др.; Ин-т химии и технологии редких элементов и минер. сырья Кол. науч. центра РАН. - № 2014126038/05; заявл. 26.06.2014; опубл. 20.11.2015, Бюл. № 32 .

6. Тюкавкина В.В., Герасимова Л.Г. Цементные композиции, модифицированные нанодисперсным диоксидом титана / Ресурсосбережение и охрана окружающей среды при обогащении и переработке минерального сырья (Плаксинские чтения 2016): Мат. Межд. конф. Санкт-Петербург, 26-30 сентября 2016 г. Санкт-Петербург: 2016. С. 612-614.

7. Gerasimova L.G., Maslova M.V., Nikolaev A.I. Synthesis of the new nano-porous titanosilicates using ammonium oxysulphotitanite. J. Glass Physics and Chemistry. 2013. V. 39. N. 5. P. 846-855.

8. Li Q., Liu Q., Peng B., Chai L., Liu H. Self-cleaning performance of $\mathrm{TiO}_{2}$-coating cement materials prepared based on solidification/stabilization of electrolytic manganese residue. Construction and Building Materials. 2016. V. 106. P. 236-242.

9. Macphee D.E., Folli A. Photocatalytic concretes - The interface between photocatalysis and cement chemistry. Cement and Concrete Research. 2016. V. 85. P. 48-54. 